\title{
Librarians and Implementation of Open Access in Universities
}

\author{
Narcisse Ekongolo Makake*, Thomas Mbila \\ Department of Library Archives and Information Sciences, Advanced School of Mass Communication, University of Yaoundé 2, Yaoundé, \\ Cameroon
}

Email address:

narso_fr@yahoo.fr (N. E. Makake), mbilathomas@yahoo.fr (T. Mbila)

${ }^{*}$ Corresponding author

\section{To cite this article:}

Narcisse Ekongolo Makake, Thomas Mbila. Librarians and Implementation of Open Access in Universities. Communication and Linguistics Studies. Vol. 5, No. 2, 2019, pp. 54-59. doi: 10.11648/j.cls.20190502.13

Received: March 15, 2019; Accepted: June 20, 2019; Published: July 1, 2019

\begin{abstract}
Over the years, university libraries have experienced several developments, one of the most emblematic of which was the introduction of information and communication technologies within these institutions. These technologies have brought significant improvements both in the management of collections by librarians and in the offer of the different services and products offered by the library. The advent of Open Access in university libraries is part of this dynamic and iterative process of innovation that the librarianship profession continues to experience. The qualitative research method permitted this paper to base on abundant literature and observations on the implementation of Open Access in Universities libraries in Cameroon, the professional and research experience of the authors. This paper supports the hypothesis that the implementation of open access in universities does not fundamentally change the librarianship profession. Instead, it provides these information professionals with other cognitive artifacts that help them to reduce the task of organizing and planning the work of a librarian. This paper therefore concludes that, despite the open access revolution, the librarian remains the main mediator of access to information and a major component in the putting in place of policies related to the creation, development and animation of open access systems in university libraries.
\end{abstract}

Keywords: Open Access, Librarianship, Information Professionals, Scientific Review, Information Gathering, Collection Expansion, Scientific Research, Access to Information

\section{Introduction}

The librarianship profession has long been conditioned by the container i.e. support (book and various type of documents), the content (information), which has almost been hidden. The advent of dematerialisation or digitisation of information, has fundamentally change the deal. The document has lost its consistency as a material object and has become fragmented and volatile. The information content takes another form, bringing into play new concepts such as information management or content management that will be used at the expense of document management. It is in this background that, Moroccan librarians such as Berrada \& Brejon de lavergnee will push this idea further by creating the concept "informatiste", which is a neologism to speak of a documentalists (librarian), who manipulates more information of various nature and form [1]. This include, information that is largely digital and spreads across computer networks, databases and the web. In this same vein, the French Association of Documentalists and Specialised Librarians (ADBS) changed its denomination to become Association of Professionals of information, but keeping the same acronym ADBS.

The main interest of professionals in the field of information is the renewal of the information functions required for library management. This renewal was initiated with the introduction of computers in the management of library operations and services, which began in the United States in the 1920s. Indeed, the first use of computers for the automation of library functions started with the management of loans, storage of information and structuring bibliographic data. These contributions will promote better management of books and documents in libraries. Then, the appearance of 
formats, like "MARC" in 1962, will bring facilities to the development of data exchange systems. In the same way, librarians will easily acquire the integrated library management systems (ILS), as these tools will prove to be relevant devices enabling librarians to satisfy their needs.

On the other hand, it is undeniable that the introduction of computers in libraries, is not easily assimilated everywhere. The amenities that these tools offer to users are incommensurable. They could now without an intermediary (the librarian), access varieties of online resources without them being accompanied by librarians. This situation inevitably compels librarians to think deeply about the role information professionals, as well as library and information units they manage. As Dominique Lahary holds, today we are witnessing the trivialisation of computer devices in libraries, and these tools, far from constituting a revolution in the practices of the information professionals, have gradually integrated universities [2]. Thus, the arrival of Open Access in university libraries is part of this long history of appropriation of technical tools by librarians.

Open Access is defined by the Berlin Declaration as " $a$ s a comprehensive source of human knowledge and cultural heritage that has been approved by the scientific community. [3]". It is therefore precisely, to put on the Internet at the disposal of the potential users, in a free and freeway, of the whole of the scientific production.

Björk and Welling equally argued that open access refers to: "the making available on the Internet of documents and scientific and technical data that everyone can freely consult, download, copy, distribute, print, index" [4]. This implies that Open Access is part of a problem of knowledge mediation which is one of the fundamental missions of both public libraries and research libraries. The questions which can be derived from this and which is acute is that: what role can the Librarian play in the implementation of Open Access in universities? What impact does the Open Access movement have on the essential missions of libraries? What changes are induced by open access to the library and information management functions? What contribution does the librarian make to book promotion in universities?

The purpose of this paper is not to present a comprehensive study on the concept of Open Access, but to offer a perspective on it, by encouraging reflections on the impact of librarians in implementing Open Access in the universities of Cameroon. This study falls in line with studies in the analysis of the use technical tools, which is a fundamental question and has being for a long time a fundamental research axis in information sciences, as well as in the Anglo-Saxon tradition of the library and information science.

\section{Research Method}

The study is based on an analysis of the scientific literature in information science (books, journal articles, thesis and dissertations) on the problems of appropriation of computer tools by librarians, the advent and the implementation of open access in university libraries. The methodology adopted was based on a qualitative survey of selected traces in scientific literature by identifying on the one hand, the new advances and breakthroughs that open access has made in the librarianship profession, and on the other hand, the invariant elements i.e. those that remain the unmovable or fundamental bases of the profession. These traces were then grouped into different thematic groups in order to construct clusters corresponding to identified categories structuring the librarianship profession. Without claiming completeness, this study surely traced only a few features of the librarianship profession, to illustrate the prevailing situation. However, traced records and their organisation nevertheless allow us to identify current trends structuring the profession of librarianship in a University milieu.

\section{Librarian's Role in the Establishment of Open Access in Universities}

To ask the question of the role of librarians in the implementation of Open Access in universities seems appropriate, this because, the initiation of a new tool in a professional world is always accompanied by a change. It can completely upset habits, or operate only slight readjustments. What is the new balance that the advent of Open Access could bring to librarianship practices? What really changes for the librarian function? and what does not change?

\subsection{Which Doesn't Really Change for the Librarianship Practice with Regard to Open Access}

Open Access is a method of disseminating knowledge available on the Internet, the full text of all scientific literature produced by researchers. This mode does not profoundly change the professional environment of librarians. This is essentially the introduction of a new tool in the kit of librarians. A tool in the computer sphere, with which librarians have already woven and continues to weave patterns of use of this artefact in their various functions. The question therefore posed, is that of the appropriation by librarians of their work tools.

Can the librarian easily take ownership of Open Access tools? The answer is positive, when we know that computers and digital objects exist in libraries, at least for research libraries, several decades ago. These libraries have more or less successfully negotiated the digital turning point. The abundance of services offered online (OPAC, databases, blogs, bibliography services, digital library, integrated library management system (IMS) attest to the fact that this strategic axis of development is well integrated into libraries.

Open Access reinforces the librarian's role as an intermediary between the user and all the information resources available in their respective institution, including the Open Access resources. These resources are information resources like any other. The librarian's job of creating links between library users and these resources, whether on site or remotely, is therefore not fundamentally shaken. The 
librarian will continue to make available to users collections that he has previously collected, processed and validated. It will always facilitate access to knowledge or where it is located and will therefore participate in the fight against the reduction of the digital divide. This further anchors the librarian in his core missions of promoting access to information and helping to meet the information expectations of its users, as it is the raison d'etre of libraries. To basically enrich users culturally and intellectually, by offering their services from collections built, Open Access therefore gives the opportunity to put at the disposition of the public and in a completely free manner, scientific and technical information and other information resources of quality.

It can therefore be said that the librarian will be able to easily appropriate Open Access technologies, that is to say, to build a strategy of adoption, assimilation or accommodation with Open Access technologies. The appropriation of Open Access technologies by librarians will inevitably be accompanied by the control of the use of Open Access tools. Proulx holds that "... the moment of appropriation is (...) the ultimate goal of the process (of use). The actual appropriation of a technology by a human agent supposes [...] the necessary and sufficient fulfilment of of three conditions: a minimal cognitive and technical control of the object or the technical device; a significant social integration of the use of this technology in the daily life of the human agent; the possibility that a gesture of creation is made possible by technology, that is to say that the use of the technical object brings out newness in the life of the user" [5].

We may think that the process of appropriation allows the integration of knowledge in a pre-existing knowledge schema. The user thus integrates the information accessed by remodeling in his own favor. It is basically a whole set of operations that allow the development of what Piaget calls " $a$ constituted knowledge" [6]. The appropriation of a tool can be considered as a relationship between a user and the technical device used. This relationship is not given, it is a construct. It therefore requires training to become familiar with the operative device. The importance of training in the ownership process can nolonger to be dismantled. Indeed, several studies (Lelong \& Thomas; Broadbent et Cara; Hert; Boullier \& Charlier; Proulx) have already shown that appropriation inevitably passes through the acquisition of a minimum of knowledge and know-how specific to the tool [7-11]. This implies that librarians' ownership of Open Access can only be effective if the librarian integrates the issue of training. The training on Open Access tool is thus one of the most essential points that brings a change in librarianship practices. The question is: what are the main elements induced by Open Access that brings about a substantial change in the librarianship profession.

\subsection{What Really Changes for a Librarian Regarding Open Access}

The adoption of Open Access by librarians may not have an impact in librarianship practices. During a technical mediation, our knowledge, our sensations do not cross the tools in a fluid way. The tool reframes, amplifies and recreates the information. The advent of a tool always imposes a certain rationality, a certain way of seeing the world, including necessarily new ways of doing things, in a word of new skills. Open Access thus imposes on the librarian new knowledge, operational know-how, professional behaviours mobilised, to face a set of cognitive problems induced by the arrival of this new technology. This situation can completely destabilise the librarian and cause a loss in pathways and achievements, that guided his functions and existence. The question is, what has Open Access fundamentally changed in the librarianship profession?

In his article, Renoult shows how the traditional document chain in libraries is undergoing important changes with the introduction of information and communication technologies. This author state that "In addition to the fact that a large part of scientific publication is digital, a key fact is that many scientific publishers are imposing economic models for the commercialization of journals on the academic world. The subscription to these scientific periodicals is mainly offered in the form of group subscriptions or bouquets," with as an alternative the articles sold by the unit (pay per view). This dominant sales mode, with contracts of great complexity, reduces the possibilities of acquisition of individual titles and restricts the scientific choices and the financial margins of maneuver of libraries" [12].

However, it should be noted that Open Access has brought into the librarianship profession a set of practices which, far from having fundamentally upset it, has changed the uses in libraries. University libraries have seen the management of collections of scientific periodicals, escaping their management functions with the advent of digital versions. Major publishers such as Reed Elsevier, who is in a monopoly position, kept digital copies on servers to build large storage of data for commercialisation. Reed Elsevier sells access to the collections as bundles. Most scientific publishers will benefit from the flexibility of the Internet to make online journals and databases accessible. They will sell access to information at high prices and offer a range of specific services, namely summary databases, links between databases, full-text articles, current awareness, document delivery and selective dissemination of information services.

As a result, libraries have increased their spending on the purchase of access licenses, at the expense of books. Some have created institutional repositories by encouraging researchers to deposit their production directly on the servers of their institutions. The creation of new institutional repositories by libraries has brought about substantial changes in the function of documented information dissemination. Collections placed online by libraries reverse the traditional meaning of documents dissemination. The library brought together externally published journals to offer to its community, while the digital library, through its institutional repositories, collect documents produced by the community to offer to the external community. Due to these aggressive commercial strategies of scientific publishers, 
what role can librarians play in the implementation of Open Access in universities?

Hence, in order to work towards the preservation of the librarianship profession, it is necessary for librarians to reposition themselves. Beyond local individualism, librarians should mutualise their efforts in order to ensure together the acquisition of electronic resources within universities and between universities. They should also emphasize the training of users in information retrieval. In this context, the library is a privileged place for learning these informational skills, and the librarian is one of the key players in this information process. This should further anchor librarians in their mission of user training, animation and the setting-up of digital collections.

\section{Role of the Librarian in Setting up Open Access in Universities}

The role of librarians in setting up Open Access in universities can be observed from several angles. We can propose three main directions. Firstly, university libraries are considered as hubs of reference in universities, as they actively participate in the fulfillment of the fundamental mission of universities i.e. to enrich and share cultural and scientific heritage. Librarians from academic institutions can use this strategic position not only to champion the cause of Open Access, but especially to convince university authorities to engage in the development of Open Access in their institutions. Secondly, librarians and libraries can choose to use their knowledge mediation skills and their capabilities as an information platform to promote the Open Access movement. Thirdly, they can act directly, by creating an Open Access feature in libraries, by accompanying their researchers in their strategies for publishing the results of their works. Universities can also publish their own resources on the Internet via Open Access technologies.

\subsection{Librarians Are Central Players in the Knowledge Mediation}

Librarians have to support and influence the implementation of Open Access in universities. Equally, academic institutions have an important role to play in the implementation of Open Access in universities. They are one of the actors most likely to work for the promotion of open access not only as part of their mission, but especially due to their proximity to academic decision-making bodies. It is also quite natural that they should give themselves an essential concern to actively participate in the implementation of Open Access in universities. They are at the heart of knowledge mediation processes and play both a supporting role in the teaching and support of studies and research. Access to knowledge is so important that it requires a lot of resources. A library alone never has the necessary means to get all the resources it needs. Therefore, they have to mutualise their resources together, so as to address the many problems they are current face and to pave a common and better perspective.

Inter-library cooperation is therefore an interesting solution when we know that it focuses on the exchange of documents, as Sanz opines "today, library co-operation appears to be even more necessary than ever before, indispensable [...] that it now extends to all areas of librarianship, whether it penetrates, discreetly or with an open face, almost every functions of the library or documentation center, even in their most everyday activities" [13].

Inter-library cooperation can take place under two main modalities, namely cooperation within a common library and information service (LIS) or in the framework of a consortium. A Common Library and Information Service is a unifying tool that seeks to identify, process, maintain and communicate all available library resources within a university. As for cooperation within consortia, which is of interest to us as part of the implementation of Open Access in universities, the focus is on combining financial and technical resources to better negotiate licenses of electronic journals with publishers. These types of cooperation are to be encouraged. The Cocurel consortium, which brings together a set of research libraries in Cameroon, can be an ideal platform for energy pooling, training, interlibrary loan of documents, without forgetting the harmonisation and judicious use of resources, which is becoming scarce because of the economic crisis.

\subsection{Librarians Are Creator of Open Access Devices in Universities}

The present economic crisis which is shaking the world has weakened libraries, which have seen their financial resources diminished considerably. This has had a negative impact on collections development: acquisitions have become scarce and subscriptions to journals have been suspended. The advent of the Open was therefore seen as a challenge to the traditional model of commercial publishing. According to Mounier, this challenge draws its legitimacy from three distinct levels of rationality: "technical, insofar as it aims to revitalize and broaden the practice of direct communication between researchers; economic, it proposes to overcome the cost barrier - caused by the dizzying inflation of some scientific journals - with new free and open -access publishing models; political, it responds to the collective expectation of global sharing of knowledge, equal access to knowledge... [14]"

The commercial edition of journals that form the basis of library collection is in the hands of a few publishers who hold a monopoly, as: Renoult: "Today, three companies alone make 15 billion euros in turnover. It is Reed Elsevier, which employs 32,000 people and has 50\% digital science, medicine, law and management; Thomson Reuters, whose digital products and services in disciplines similar to those covered by Reed Elsevier account for 90\% of the business; and Wolters Kluwer (Amsterdam)" [15]. Faced with this escalation, libraries are coming together to set-up consortiums grouping several libraries, not only to better 
negotiate with journal publishers, but more especially to mount projects to build their own Open Access repositories (open archives), providing free access with any form of financial compensation to scientific publications.

Therefore, librarians, especially those in research libraries, who make extensive use of scientific journals, should firstly convince their institutions to become producers of scientific content. On the other hand, they should convince and even compel their researchers to deposit their publications in the institutional repositories that librarians would have previously created and organised. The increase in the size of these databases can respond to two main modalities: firstly, Librarians can "impose" a kind of legal deposit on all publications produced within the framework of the university (thesis, dissertations, reports, syllabuses, bibliographies, etc); secondly, the entry of documents in an Open Access system of a library, can consist of a policy with objective to encourage scientists to develop a culture of depositing their publications, as this increases their visibility and the possibility to increase their citation count. On the mandatory deposit of scientific publications, Rentier explains that, The best incentive is the significant increase in reading their works and, therefore, an increase of their citation index [16].

Another argument militating for the need to convince researchers to deposit their work in institutional repositories is the exceptional nature of the product of scientific research, which in Cameroon is a product largely subsidised by the State through research grants allocated to researchers, including research missions in and out of the country. This therefore makes scientific publications a kind of "public good", produced by researchers and paid by public funds. According to UNESCO's Global Open Access Portal, with about 1200 scientific articles and theses produced by public universities, Cameroon could set up an extensive research reservoir, considering that the country counts eight public universities, more than a hundred private higher education institutions and over 700 laboratories [17]. Thus, librarians need to take advantage of their central role at the very heart of knowledge mediation systems to fully participate in the collection and dissemination of university scientific productions. We can therefore say that librarians of academic institutions will therefore be very much in his role when advocating for the establishment of Open Access systems in Cameroonian universities.

\section{Conclusion}

In the framework of this paper, it should be noted that practices do not change as quickly as one can think. Indeed, the advent of open access has not altered the fundamental mission of librarians, which remains to provide citizens greater access to knowledge and culture. However, it should still be noted that the digital revolution and its avatars such as open access have had an impact on the function and practice of librarianship, with changes in services offered, users' expectations, the image of Librarians and their profession. Indeed, open access has fostered the emergence of new producers (aggregators), new access tools (search engines, platforms, Web applications 3.0), new methods of providing information and legitimacy (everyone can be author, journalist, photographer, computer experts, etc.)

Open access has also brought greater openness and cooperation. In terms of openness, the library now provides access to many more documents than before. There is thus a greater circulation of knowledge, information and contents in the library milieu. In terms of cooperation, there is a far greater flow and exchange of content between university libraries, which have come together to form a consortium, in order to better organise access to electronic journals, as well as open archives, to contribute in electronic deposit of theses and to develop the institutional digital reservoirs.

\section{References}

[1] L Berrada, \& M.-E Brejon de Lavergnee, «Ecole des sciences de l'information de Rabat», Gazette des archives, no. 132, 1986, pp32-40.

[2] D. Lahary, «Informatique et bibliothèques. Bulletin des bibliothèques de France» $\mathrm{n}^{\circ}$ 1, 2002 [on line], $<$ http://bbf.enssib.fr/consulter/bbf-2002-01-0060-006>.

[3] Berlin Declaration on Open Access to Knowledge in the Sciences and Humanities. october 2003 [on line], $<$ https://openaccess.mpg.de/Berlin-Declaration>.

[4] B-C Björk, P Welling, M Laakso, P Majlender, T Hedlund, "Open Access to the Scientific Journal Literature: Situation 2009" 2010.

[5] S Proulx,. «Les formes d'appropriation d'une culture numérique comme enjeu d'une société du savoir » in Actes du colloque COREVI «Gouvernance et usages d'Internet: vers un nouvel environnement normatif », Montréal, 2001.

[6] J. Piaget, Biologie et connaissance. Paris: Gallimard, 1967.

[7] B. Lelong, F Thomas, «L'apprentissage de l'internaute: socialisation et autonomisation " in Actes du 3e colloque international ICUST $2001 \mathrm{Du} 12$ au 14 juin, Paris (France), 2001, p. 74-85.

[8] S. Broadbent, F. Cara «Évolution des usages de l'Internet » in E. Guichard (Ed.), Comprendre les usages d'Internet Paris: Éditions ENS, 2001, p. 156-164.

[9] P. Hert, «Quelques usages des technologies de communication dans les sciences » in Actes du 1er Colloque international Penser les usages. Du 27 au 29 mai, Arcachon, 1997.

[10] D. Boullier, C. Charlier, «À chacun son Internet. Enquête sur des usagers ordinaires » in Réseaux, n86, 1997, p. 159-181.

[11] S. Proulx, Vivre avec l'ordinateur: les usagers de la microinformatique. Boucherville, QC: Editions G. Vermette, 1988.

[12] D Renoult, «Bibliothèques de recherche et mondialisation » in Gérard Fussman (dir.), La mondialisation de la recherche Collège de France, 2011.

[13] S. Gonzalès, L'Etat, les bibliothèques territoriales et la coopération: l'expérience rennaise, Lyon ENSSIB, p. 28 2010. 
[14] P. Mounier, «Le libre accès : entre idéal et nécessité», Hermès, $\mathrm{n}^{\circ} 57$, «Sciences.com. Libre accès et science ouverte», 2010, p. 23-24.

[15] D Renoult, «Bibliothèques de recherche et mondialisation » in Gérard Fussman (dir.), La mondialisation de la recherche Collège de France, 2011.
[16] B. Rentier, «Chercheurs, vos papiers! Les dépôts institutionnels obligatoires», Hermès, $\mathrm{n}^{\circ} 57$, «Sciences.com. Libre accès et science ouverte », 2010, p. 108.

[17] Unesco, http://www.unesco.org/new/en/communication-andinformation/portals-and-platforms/goap/. 